\title{
What is the optimal intake of vitamin $\mathrm{C}$ ?
}

\author{
Manfred Eggersdorfer \\ UMCG, Groningen, Netherlands
}

\section{Abstract}

Vitamin $\mathrm{C}$ is an essential nutrient which humans cańt produce. Vitamin $\mathrm{C}$ has many important functions in the body, such as immune-system stimulation, growth and repair of tissue, sustain cardiovascular and bone health and protecting cells from oxidative stress by neutralizing harmful free radicals.

To ensure adequate vitamin $\mathrm{C}$ levels intake recommendations are set.

A minimum of $10 \mathrm{mg} /$ day is needed to prevent scurvy, the clinical manifestation of vitamin $\mathrm{C}$ deficiency. Some countries like UK and Australia and the FAO/WHO* refer to this and set recommendations of $40-45 \mathrm{mg} / \mathrm{day}$ including a safety margin.

Later findings showed that vitamin $\mathrm{C}$ is essential for further functions, especially for the immune system. In addition, kinetic studies in healthy men showed that the saturation of neutrophil leukocytes and plasma needs higher vitamin $\mathrm{C}$ intakes. Based on the content parameters of plasma level, neutrophil saturation, and minimal urinary loss, the intake recommendations were increased in some countries. The IoM (US) increased the vitamin C recommendations (RDA) to $90 \mathrm{mg}$ and $75 \mathrm{mg} / \mathrm{day}$ and EFSA to $110 \mathrm{mg}$ and $95 \mathrm{mg} /$ day for men and women, respectively.

It's recommended to define intake recommendations based on functional parameters because vitamin $\mathrm{C}$ levels should be at a level that assures optimal functioning of all processes requiring vitamin $\mathrm{C}$. Lack of overt deficiency does not necessarily indicate adequacy of intake. Up to now no sufficient evidence exists for a functional parameter.

Recent science from an in-vitro and a human intervention study in healthy men investigated the effects of vitamin $\mathrm{C}$ on the leukocyte function. The results support neutrophil motility as a suitable functional parameter. The observed effects indicate to increase the intake recommendation to $200 \mathrm{mg} /$ day for healthy persons. This is in line with established knowledge from pharmacokinetic, observational, and intervention studies. Plasma vitamin C saturation occurs at a daily intake of $200 \mathrm{mg} / \mathrm{day}$ and a recent review showed that supplementation of at least $200 \mathrm{mg}$ / day reduced the duration of common cold significantly in children as well as in adults. Additionally, it could be shown that incidences of cardiovascular disease were lowest with vitamin $\mathrm{C}$ intakes of at least $200 \mathrm{mg} / \mathrm{day}$.

These findings indicate that an increase of current intake recommendations to $200 \mathrm{mg} /$ day would be beneficial for the function of the immune system, thus for human health.

\section{Conflict of Interest}

I am consulting ingredient, food and supplement companies 